Article

\title{
Experimental Study on the Adhesion of Basalt Textile Reinforced Mortars (TRM) to Clay Brick Masonry: The Influence of Textile Density
}

\author{
Giuseppe Ferrara ${ }^{1,2}\left(\mathbb{0}\right.$, Carmelo Caggegi $^{1, *}$, Aron Gabor ${ }^{1}$ and Enzo Martinelli ${ }^{2}$ (D) \\ 1 Laboratory of Composite Materials for Construction (LMC2), University Claude Bernard Lyon 1, Site Bohr, \\ 82 Boulevard Niels Bohr, Campus de la Doua, CEDEX, 69622 Villeurbanne, France; giferrara@unisa.it (G.F.); \\ aron.gabor@univ-lyon1.fr (A.G.) \\ 2 Department of Civil Engineering, University of Salerno, Via Giovanni Paolo II 132, 84084 Fisciano, Italy; \\ e.martinelli@unisa.it \\ * Correspondence: carmelo.caggegi@univ-lyon1.fr
}

Received: 16 August 2019; Accepted: 24 November 2019; Published: 29 November 2019

\begin{abstract}
Textile Reinforced Mortar (TRM) composite systems are gaining consensus within the scientific and technical communities as a viable and advantageous alternative to the most conventional Fibre-Reinforced Polymer (FRP) composites. Due to the good compatibility both in terms of stiffness and vapor permeability between the inorganic matrix and the substrate, the TRMs appear to be particularly well suited for strengthening masonry members and enhancing their capacity to withstand tensile and shear stresses, such as those induced by seismic shakings. This paper aims to investigate the mechanical response of a TRM system featuring an internal reinforcement made of basalt fiber textile. Therefore, the paper reports the results of an experimental campaign carried out by single-lap shear bond tests on masonry substrate reinforced by TRM strips. Three different kinds of TRM have been taken into account, each one characterized by a variable number of fabric plies. The results show that, in all cases, TRMs fail prematurely due to debonding between fabric and matrix. However, the aforementioned premature failure is the main concern emerging from these test results, and further work is requested in reformulating the matrix composition towards enhancing their tensile strength and, hence, restraining the occurrence of fabric-to-matrix debonding.
\end{abstract}

Keywords: basalt-TRM; basalt-FRCM; shear bond test; tensile test; natural composites; basalt fibers

\section{Introduction}

Nowadays, the use of externally bonded Textile Reinforced Mortar (TRM) systems in the structural repair and rehabilitation of existing members and structures is steadily gaining consensus within the technical community and, hence, it is getting more and more common as a viable alternative to the use of Fiber Reinforced Polymer (FRP) systems [1]. In fact, the former have the potential to outperform the latter in several aspects, such as fire resistance, reversibility of the installation process, vapor permeability, and a physical/chemical compatibility with the substrate, especially when applied to masonry elements [2].

Due to the great interest in the application of TRM systems, standards, and guidelines have been developed in order to help meet the needs of practitioners working in the existing structures' retrofitting field. In the US, a guide to design "Externally Bonded Fabric-Reinforced Cementitious Matrix Systems" [3] and acceptance criteria for their mechanical characterization [4] has been implemented. In Europe, scientific committees have been created to define recommendations concerning a qualification procedure for TRM composites by means of tensile [5] and TRM-to-substrate bond [6] tests. Moreover, 
materials' identification procedures [7] and instructions for the design of structural retrofitting interventions by means of TRMs [8] was recently provided in Italy.

In recent years, many experimental research studies have been carried out to characterize the mechanical behavior of TRM systems performed by using different types of textiles such as carbon, glass, steel, PBO (poly para phenylene benzobisoxazole), and basalt. Several studies have focused on the tensile strength of TRM coupons subjected to uniaxial tensile tests [9-13]. These studies showed that the typical TRM tensile response is characterized by a trilinear response with the first elastic branch, the second stage characterized by development of cracks within the matrix, and the third stage in which the response is mainly governed by the reinforcing textile. Durability aspects were investigated in order to define the mechanical behavior of TRM systems subjected to aggressive environmental exposures. It was shown that alkaline and saline environments may reduce the performance of TRM systems, even though alkali resistant textiles are employed, due to the decrease of strength of the mortar $[14,15]$. In some studies, the issue of the mechanical behavior of TRM systems subjected to high temperature conditions was addressed. It was shown that the use of appropriate textile coating plays a key role: in the case of coating procedures not specifically designed to resist to high temperature, the mechanical response may result much worse than the response of system characterized by dry fibers; conversely, specifically designed coating systems may confer to the TRM significant improvements in terms of strength at high temperatures [16,17]. The influence of freeze-thaw and heat-rain cycles on the mechanical response of TRM systems was analyzed as well by showing that significant decays of the mechanical properties may occur under these loading conditions due to the formation of microcracks in the matrix and the hydration of unreacted cement particles with consequent and damage of the textile $[18,19]$. The bond behavior of the composite system with either masonry or concrete substrates has been investigated by means of adherence tests. Different test set-ups were adopted to investigate this aspect such as double-lap shear configuration [20], push-pull double lap joints configuration [21], and single shear lap test [6]. The latter is considered as the most suitable test to characterize the TRM-to-substrate bond behavior due to it easy reproducibility. Depending on the materials' properties, such as nature of the substrate, matrix strength, textile stiffness, the failure mode may interest the substrate-matrix interface, textile-matrix interface, or fiber failure [22-25]. Moreover, investigations were carried out by adopting plant fibers, such as hemp, flax, sisal, and coir, as reinforcement of TRM systems, showing the latter as a potential solution to increase the sustainability of the systems but still characterized by mechanical issues mainly related to the low stiffness of the textile, adherence properties, and durability aspects [26-30].

The composite system, consisting of textile embedded in mortar, once applied on a substrate can exhibit its maximum capacity with a rupture of the fibers or with an adherence crisis at one of the interface surfaces between the different materials.

According to the employed materials and to the nature of the substrate, one of the two failure modes, or a combination of the two, may occur. Experimental evidence shows that the bond at the matrix-fiber interface frequently represents the weakness of TRM composite systems. As a matter of fact, the slippage of the textile roving from the mortar is the most common failure mode observed in shear bond tests; it has been underlined by the Round Robin test carried out by the Technical Committee TC 250 CSM RILEM (International Union of Laboratories and Experts in Construction Materials, Systems and Structures) [31-35]. Therefore, the stress acting on the fibers at failure is frequently lower than the corresponding tensile strength of the fibers [36]; hence, the potential strength of the system is not entirely exploited.

Aiming to improve the capacity of the whole system, specifically designed solutions may be adopted by treating the fibers or the mortar to increase the textile-to-matrix bond strength. Similarly, the mechanical response may be changed by acting on the amount of the reinforcing textile. In fact, a higher amount of textile may increase the maximum capacity of the composite system and theoretically lead to different failure modes, such as a debonding at the TRM-to-substrate interface. 
Based on the assumption that increasing axial stiffness of the reinforcing fabric leads to increasing axial stiffness of TRM too [37], this paper aims to analyze how the amount of textile affects the bond behavior of Basalt Textile Reinforced Mortar (BTRM) systems applied to masonry substrate. As a matter of fact, few experimental research studies are currently available on this aspect and controversial results emerge from them by showing in some cases a decrease of the system capacity due to the reducing of the textile space between the threads [38], in others a general improvement of the mechanical response by increasing the amount of reinforcement textile [39].

Therefore, this study aims at shedding a clarifying light on the interaction between TRM and masonry with reference to a composite material internally reinforced with basalt textile (BTRM). Among the various types of fibers available on the market, basalt textiles represent one of the most promising thanks to their mechanical properties [40], their durability [41], and their non-toxic nature [42]. Several research studies have been carried out showing the potential of BTRM composite systems both on a small scale $[43,44]$ and on larger scales as reinforcement of wall panels $[45,46]$.

The results of single-lap shear bond tests are presented in this work, in order to investigate, under shear load conditions, how the amount of textile may affect the load capacity. Specifically, three series of specimens were performed respectively reinforced by one, two, and three plies of textile, corresponding to three, five, and seven basalt rovings. Tensile tests on BTRM systems reinforced with the same roving arrangement have been carried out in a previous related study [47]. In the paper, a comparison between the composite performances in tension and shear is also shown.

\section{Materials and Methods}

\subsection{Materials}

Single-lap shear bond tests are carried out on masonry substrates reinforced by BTRM systems. The mechanical properties of bricks, mortar joints (substrate), TRM mortar matrix, and basalt textile are shown in Table 1.

Table 1. Mechanical properties of the specimen components (Coefficient of Variation in round brackets).

\begin{tabular}{|c|c|c|c|c|c|c|c|}
\hline \multirow{3}{*}{$\begin{array}{l}\text { Masonry } \\
\text { substrate }\end{array}$} & \multirow{3}{*}{$\begin{array}{l}\text { Bricks * } \\
\text { Mortar }\end{array}$} & \multicolumn{2}{|c|}{$f_{c}\left(\mathrm{~N} / \mathrm{mm}^{2}\right)$} & \multicolumn{2}{|c|}{$f_{t}\left(\mathrm{~N} / \mathrm{mm}^{2}\right)$} & \multicolumn{2}{|c|}{$E_{c}\left(\mathrm{~N} / \mathrm{mm}^{2}\right)$} \\
\hline & & 17.89 & $(5 \%)$ & 2.46 & $(11 \%)$ & 5756 & $(5 \%)$ \\
\hline & & 10.93 & $(7 \%)$ & 3.08 & $(6 \%)$ & & \\
\hline \multirow{2}{*}{ TRM system } & Cementitious matrix & 20.56 & $(16 \%)$ & 5.46 & $(12 \%)$ & \multirow{2}{*}{\multicolumn{2}{|c|}{55,825}} \\
\hline & Basalt textile ** & \multicolumn{2}{|c|}{ - } & 1089 & & & \\
\hline
\end{tabular}

$f_{c}=$ compressive strength, $f_{t}=$ tensile strength, $E_{c}=$ elastic modulus in compression

${ }^{*}$ values derived from [48]; ** values derived from [47].

The masonry substrate is characterized by five bricks and four mortar joints. The clay bricks, belonging to the commercial line "Rosso Vivo A6R55 W" produced by San Marco-Terreal, Valenza AL, Italia [49], are $250 \mathrm{~mm}$ long, $120 \mathrm{~mm}$ wide, and $55 \mathrm{~mm}$ thick.

Hydraulic lime-based mortar is used to assembly masonry bricks. Its composition is characterized by 1 part cement, 2 parts hydraulic lime, and 3 parts sand, using a water-cement ratio equal to 0.3 . Twelve hydraulic lime mortar specimens, prismatic in shape $\left(160 \times 40 \times 40 \mathrm{~mm}^{3}\right)$, were subjected to three-point bending tests in order to assess the tensile strength $f_{t}$, as suggested by the standards [50]. Uniaxial compression test was carried out on each half-prism resulting by the bending test to assess the compressive strength $f_{c}$.

The BTRM system adopted in the study consists of basalt textile embedded in a one-component dry thixotropic mortar mix containing redispersible polymers. The textile is a bi-directional open waved basalt fabric characterized by a special high-temperature resistive coating for stability belonging to the commercial line "Tyfo ${ }^{\circledR}$ EP-B Basalt fabric" produced by Fyfe Company, San Diego, CA, USA [51]. The mesh is characterized by a clear distance between centerlines of the threads of $25 \mathrm{~mm}$ in both the directions (Figure 1). 


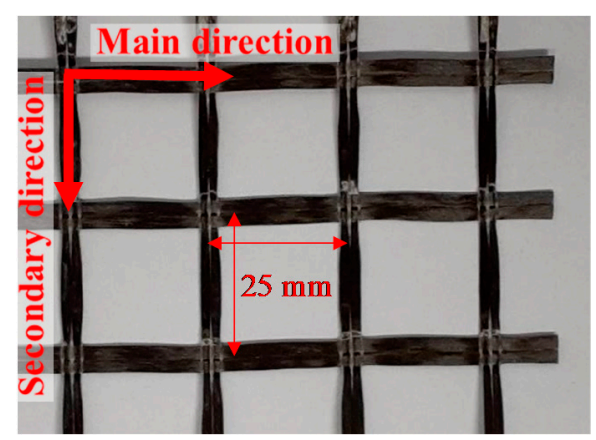

Figure 1. Bi-directional basalt textile.

The same protocol of test applied to define the mechanical properties of the substrate mortar has been reproduced to define the tensile and compressive strength concerning the BTRM matrix. The mechanical characterization was carried out after 28 days of curing ( $22.5 \pm 2.5 \mathrm{C}, 60 \pm 10 \%$ of humidity). The morphology of the textile threads was analyzed by means of X-ray tomography carried out in previous studies [47] by giving a value of the thread cross-section equal to $1.61 \mathrm{~mm}^{2}$.

\subsection{Methods}

Shear bond tests were carried out by adopting the single-lap shear test (SST) configuration aiming to reproduce an intermediate crack-induced failure mode, characterized only by shear stress distributed on the interfacial surface between the support material and the reinforcing system. In order to be consistent with studies present in literature, the recommendation of the committee TC 250 CSM RILEM [6] had been taken into account to define the experimental setup and the mechanical parameters in study.

The specimens consist of prismatic masonry substrate made up of five clay bricks and four $10 \mathrm{~mm}$ thick mortar joints, reinforced by a BTRM strip. A cross-section of $90 \times 10 \mathrm{~mm}^{2}$ and a bond length of $260 \mathrm{~cm}$ characterize the BTRM reinforcing system, placed centrally along the vertical axis of the prism and at a distance of $20 \mathrm{~mm}$ from the upper side of the support (Figure 2).
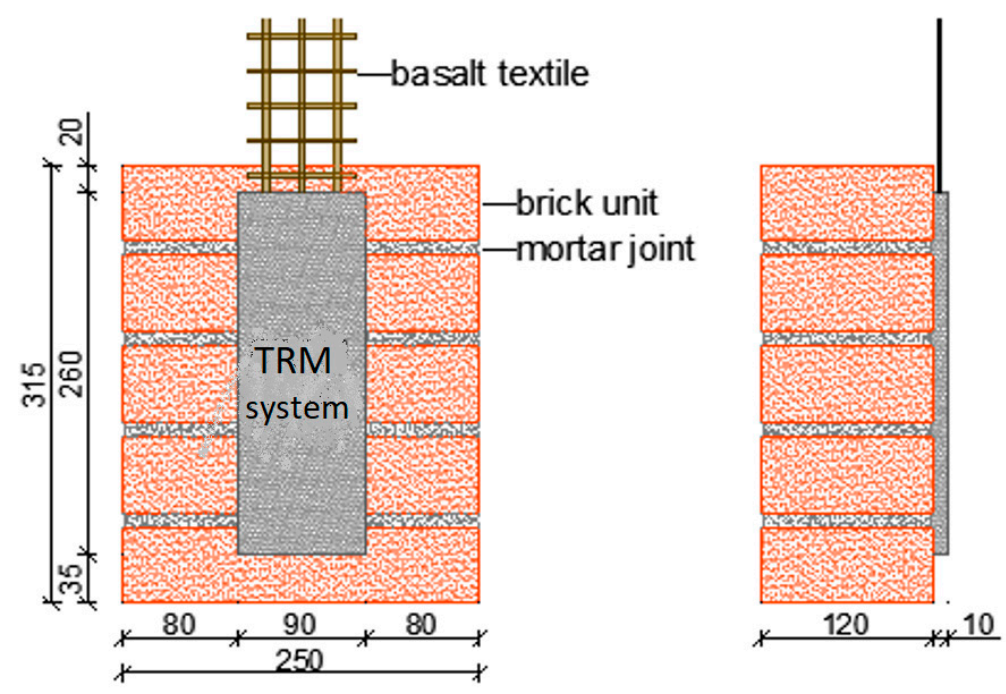

Figure 2. Specimens' geometry (measures in $\mathrm{mm}$ ).

Different numbers of basalt textile layers characterize the three series of specimens conceived to analyze the influence of the amount of reinforcing fabric on the adherence behavior of the entire system. The three series of specimens considered are respectively named SST_T1, SST_T2, SST_T3, where SST refers to the Single Shear Test employed, T1, T2, and T3 represent the reinforcing configurations 
characterized by either one, two, or three overlapped basalt textile layers (Figure 3). The main properties of the three series of specimens are reported in Table 2.

a)

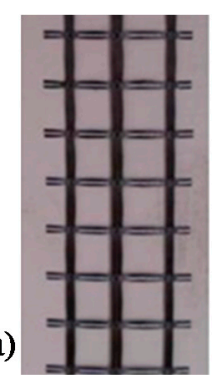

b)

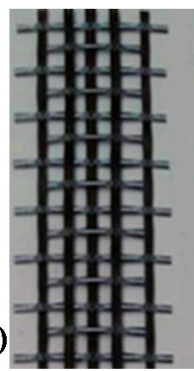

c)

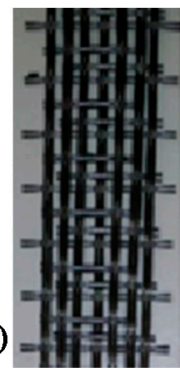

Figure 3. Reinforcing textile configuration arrangements: (a) T1; (b) T2; (c) T3.

Table 2. Characteristics of the series of specimens tested.

\begin{tabular}{cccccc}
\hline $\begin{array}{c}\text { Series of } \\
\text { Specimens }\end{array}$ & $\begin{array}{c}\text { Number of } \\
\text { Specimens }\end{array}$ & $\begin{array}{c}\text { Number of } \\
\text { Threads }\end{array}$ & $\begin{array}{c}\text { Textile Cross } \\
\text { Section } \mathbf{~ m m}^{\mathbf{2}}\end{array}$ & $\begin{array}{c}\text { Textile Density } \\
\mathbf{g} / \mathbf{m}^{\mathbf{2}}\end{array}$ & $\begin{array}{c}\text { Volumetric } \\
\text { Strength Ratio }\end{array}$ \\
\hline SST-T1 & 5 & 3 & 4.83 & 220 & $0.53 \%$ \\
SST-T2 & 4 & 5 & 8.05 & 367 & $0.89 \%$ \\
SST-T3 & 6 & 7 & 11.27 & 513 & $1.25 \%$ \\
\hline
\end{tabular}

The reinforcing configurations $\mathrm{T} 2$ and $\mathrm{T} 3$ are obtained by overlaying two or three plies of fabric so that the spacing of the mesh is reduced. For all the specimens, the reinforcement is placed at the middle-thickness of the BTRM strip.

The single shear-lap tests were carried out by using an electro-mechanical testing machine, with a $50 \mathrm{kN}$ capacity in traction and compression, in displacement control using a cross-head rate of $0.3 \mathrm{~mm} / \mathrm{min}$. A steel system, consisting of two metallic plates connected by four threaded rods, locked the masonry prisms so that no rotation of the reinforced substrate may occur (Figure 4a).

a)

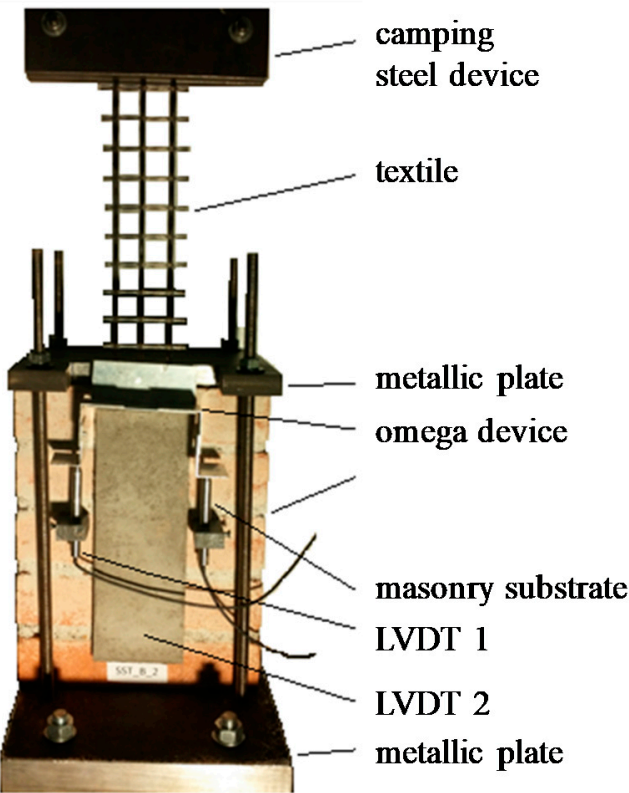

\section{Metallic hinge system}

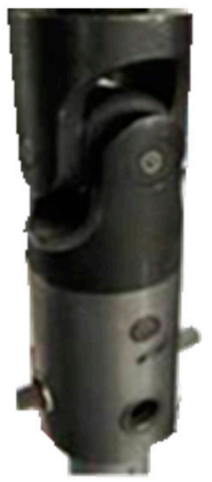

b)

Figure 4. (a) test set-up of single-shear lap tests; (b) particular of the metallic hinge system.

The steel plates bonded to the end of the basalt fabric are grabbed by a clamping steel device. In order to avoid load eccentricity and, consequently, tensile normal stresses (peeling) at the interface surface between the masonry substrate and the reinforcing system; each specimen was duly placed to 
ensure the textile to be aligned with the direction of the load, with no intentional eccentricity. Moreover, a hinge is placed between the clamping steel device and the traverse of the universal machine so that no bending moment could be transmitted to the BTRM system (Figure $4 \mathrm{~b}$ ).

In order to record possible slipping of the textile within the mortar matrix, an aluminum device, named " $\Omega$ " for its shape, was bonded to the basalt textile. Two LVDTs (Linear Variable Differential Transformer) bonded to the masonry substrate, are used to monitor the motion of the " $\Omega$ " stub during the test.

\section{Results}

The response obtained from the shear bond tests is expressed herein in terms of stress-slip $(\sigma-s)$. The stress " $\sigma$ " is obtained by dividing the applied load for the cross-section of textile; the slipping " $s$ " of the textile within the mortar matrix is computed as the average value among the two displacements recorded by the transducers (LVDT 1 and 2) monitoring the " $\Omega$ " device.

The stress-slip response concerning the three series of specimens is shown in Figure 5. The main parameters obtained from the tests are listed in Table 3. For each specimens, the maximum value of the load, $P_{u}$, the corresponding displacement of the " $\Omega$ " device, $s^{*}$, and the corresponding average value of the normal stress reached by the basalt textile, $\sigma^{*}$, are evaluated. The stiffness of the reinforcing system in the linear branch, $k_{0}$, defined as the ratio between the load, and the corresponding displacement in the elastic branch of the curve is computed as well. The elastic energy of the system, $\Gamma_{e l}$, and the inelastic energy, $\Gamma_{i n}$, computed as the area underlying the force-displacement curve respectively in the elastic and post-peak phase, were reported in the table.

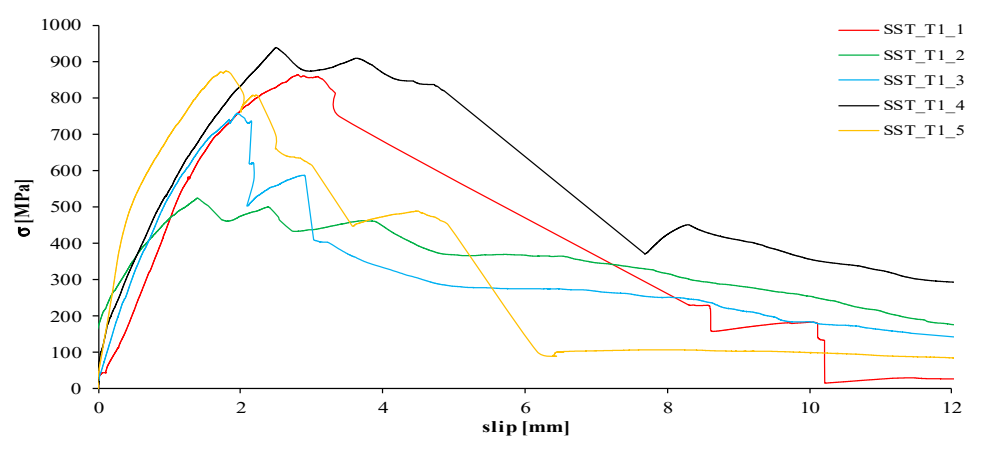

(a)

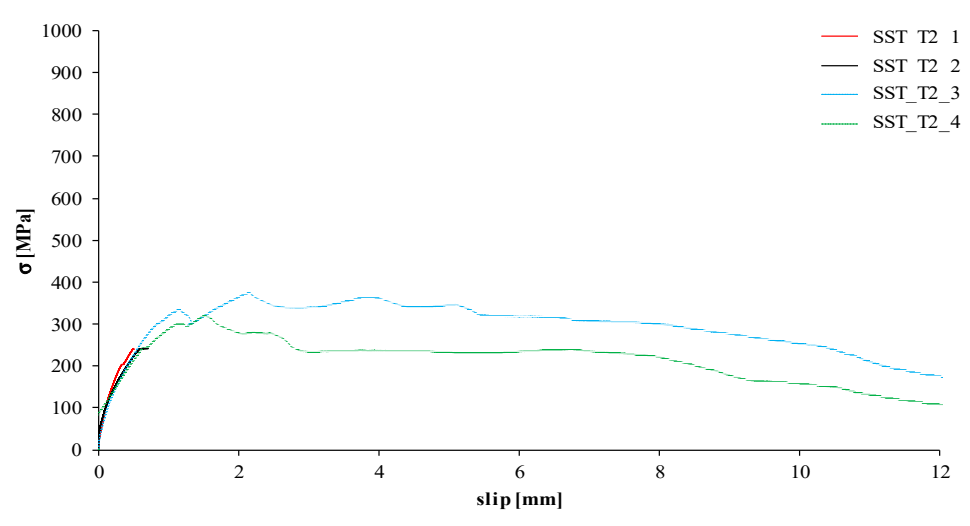

(b)

Figure 5. Cont. 


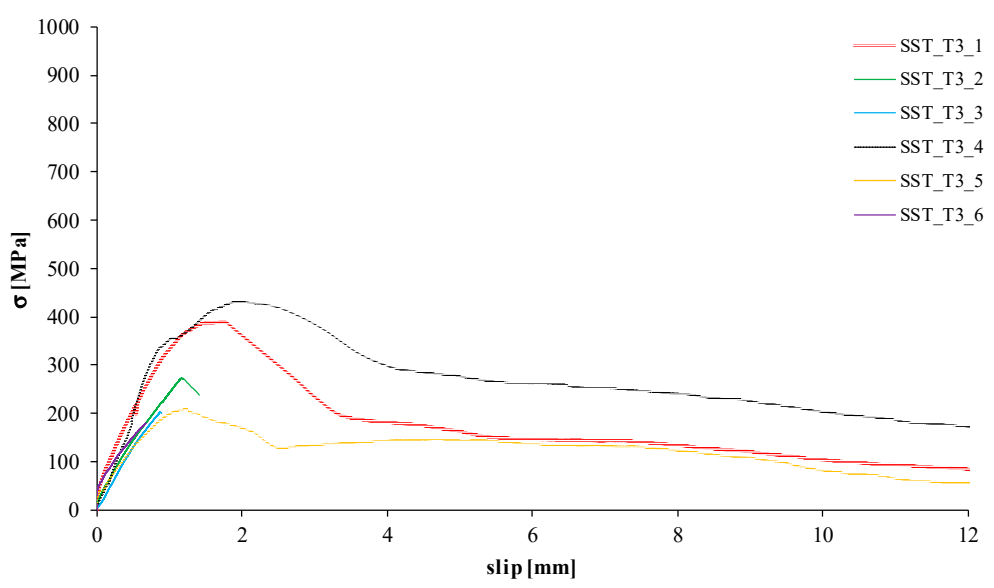

(c)

Figure 5. Stress-slip curves of shear bond tests on series: (a) SST_T1; (b) SST_T2; (c) SST_T3.

Table 3. Shear bond test parameters for series SST-T1, SST-T2 and SST-T3.

\begin{tabular}{|c|c|c|c|c|c|c|c|c|c|c|c|c|c|c|}
\hline & Specimen & $\begin{array}{c}P_{u} \\
\text { N }\end{array}$ & & $\begin{array}{c}s^{*} \\
\mathrm{~mm}\end{array}$ & & $\begin{array}{l}k_{o} \\
\mathrm{~N} / \mathrm{mm}\end{array}$ & $\begin{array}{l}\sigma^{*} \\
\mathrm{~N} / \mathrm{mm}^{2}\end{array}$ & $\sigma^{*} / f_{t}$ & & $\begin{array}{c}\Gamma_{e l} \\
\mathbf{J}\end{array}$ & & $\stackrel{\Gamma_{i n}}{\mathrm{~J}}$ & & $\begin{array}{c}\text { Failure } \\
\text { mode }\end{array}$ \\
\hline SST-T1 & 1 & 4301 & & 3.45 & & 2433 & 890.4 & 0.85 & & 7.4 & & 17.6 & & $\mathrm{D}+\mathrm{F}^{*}$ \\
\hline SST-T1 & 2 & 2613 & & 1.39 & & 1322 & 541.0 & 0.51 & & 2.6 & & 22.0 & & $\mathrm{D}$ \\
\hline SST-T1 & 3 & 3772 & & 1.95 & & 3607 & 781.0 & 0.74 & & 4.5 & & 18.9 & & $\mathrm{D}+\mathrm{F}$ \\
\hline SST-T1 & 4 & 4672 & & 2.49 & & 1991 & 967.3 & 0.92 & & 7.2 & & 34.9 & & $\mathrm{D}+\mathrm{F}^{*}$ \\
\hline \multirow[t]{2}{*}{ SST-T1 } & 5 & 4353 & & 1.8 & & 5767 & 901.2 & 0.86 & & 5.4 & & 15.6 & & $\mathrm{D}+\mathrm{F}^{*}$ \\
\hline & Mean (Co.V. \%) & 3942 & (21) & 2.22 & (36) & $3024 \quad(58)$ & 816.2 (21) & 0.78 & (21) & 5.4 & (36) & 21.8 & (35) & - \\
\hline SST-T2 & 1 & 2728 & & 0.5 & & 5387 & 338.9 & 0.32 & & 0.9 & & - & & $B+C$ \\
\hline SST-T2 & 2 & 2731 & & 0.64 & & 3319 & 339.3 & 0.32 & & 1.2 & & - & & B \\
\hline SST-T2 & 3 & 4225 & & 2.16 & & 3379 & 524.8 & 0.50 & & 6.7 & & 35.6 & & E \\
\hline \multirow[t]{2}{*}{ SST-T2 } & 4 & 3619 & & 1.51 & & 2733 & 449.5 & 0.43 & & 4.0 & & 26.0 & & $\mathrm{E}$ \\
\hline & Mean (Co.V. \%) & 3326 & (22) & 1.20 & (65) & $3705 \quad(31)$ & $413.1 \quad(22)$ & 0.39 & (22) & 3.2 & (85) & 30.8 & (22) & - \\
\hline SST-T3 & 1 & 5650 & & 1.75 & & 4985 & 501.3 & 0.48 & & 6.8 & & 27.1 & & $\mathrm{E}$ \\
\hline SST-T3 & 2 & 3956 & & 1.17 & & 3105 & 351.0 & 0.33 & & 2.7 & & - & & $\mathrm{C}$ \\
\hline SST-T3 & 3 & 2938 & & 0.87 & & 3529 & 260.6 & 0.25 & & 1.4 & & - & & $\mathrm{C}$ \\
\hline SST-T3 & 4 & 6250 & & 1.99 & & 6979 & 554.6 & 0.53 & & 8.6 & & 44.2 & & $\mathrm{E}$ \\
\hline SST-T3 & 5 & 3041 & & 1.24 & & 2454 & 269.8 & 0.26 & & 2.5 & & 20.7 & & $\mathrm{E}$ \\
\hline \multirow[t]{2}{*}{ SST-T3 } & 6 & 2656 & & 0.71 & & 3179 & 253.7 & 0.22 & & 1.3 & & - & & $\mathrm{C}$ \\
\hline & Mean (Co.V. \%) & 4082 & (37) & 1.29 & (38) & $4038 \quad(41)$ & $362.2(37)$ & 0.34 & (37) & 3.9 & (80) & 30.7 & $(40)$ & - \\
\hline
\end{tabular}

$P_{u}=$ peak load, $s^{*}=$ displacement at peak load, $k_{o}=$ initial stiffness, $\sigma^{*}=$ stress at peak load, $f_{t}=$ basalt tensile strength, $\Gamma_{e l}=$ elastic energy, $\Gamma_{\text {in }}=$ inelastic energy.

In order to quantify the loading of the fibers, the ratio between the maximum stress, $\sigma^{*}$, and the tensile strength of the textile, $f_{t}$, is also reported for each specimen.

The failure mode during shear bond tests highlighted the weakness of the system and allowed for investigating the effectiveness of the substrate-to-reinforcement load transfer. In fact, depending on the mechanical properties of the matrix and the textile, and the bond relationship at both interface surfaces textile-to-matrix and matrix-to-masonry, different failure modes may occur. Typical externally bonded strengthening systems' failure configurations are shown in Figure 6 [36]: debonding with cohesive failure of the substrate (A), debonding at the matrix-to-substrate interface (B), debonding at the textile-to-matrix interface (C), textile slippage within the mortar matrix (D), textile slippage within the matrix with cracking of the outer layer of mortar (E), and tensile rupture of the textile out of the bonded area $(\mathrm{F})$. A further failure mode $\mathrm{F}^{*}$ is considered to describe the tensile rupture of the textile within the mortar matrix. For each specimen, its failure mode is discussed as well. 


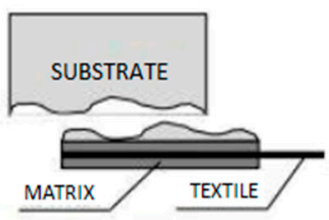

A

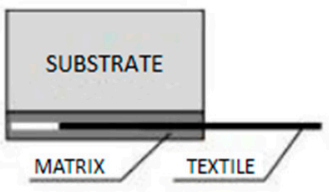

$\mathrm{D}$

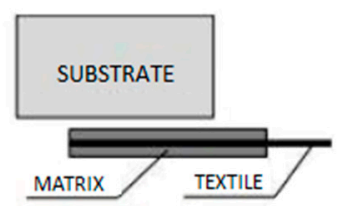

B

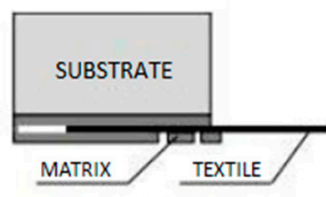

E

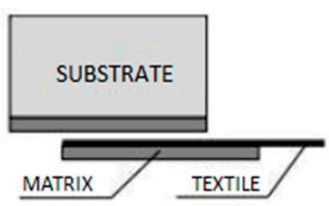

$\mathrm{C}$

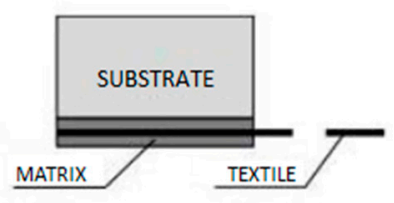

F

Figure 6. Failure modes in shear bond test on TRM-to-masonry systems: (A) cohesive failure of the substrate; (B) debonding at TRM-to-substrate interface; (C) debonding at textile-to-matrix interface; (D) textile slippage; (E) textile slippage with matrix cracking; (F) textile rupture [32].

\section{Discussion}

Analyzing the shear bond test curves, it is possible to recognize two main different responses. All the specimens of the SST-T1 series, and some of the other two, exhibited an elastic behavior up to the achievement of the peak load; consequently, a drop of the load leads to a post-peak phase mainly characterized by a quite flat branch of the curve due to the slipping of the basalt threads within the mortar (failure modes D, E, and F). Some others exhibited an elastic brittle behavior characterized by lower maximum loads. This behavior, occurring in some specimens reinforced with one or two layers of textile, is due to an abrupt detachment of the outer layer of mortar from the inner one (failure modes $\mathrm{B}$ and $\mathrm{C}$ ). In general, the results in terms of first stage stiffness, $k_{0}$, and displacement, $s^{*}$, resulted in being characterized by a high scatter as shown by the coefficients of variation. This dispersion may be attributed to two aspects concerning both the test equipment and the specimens' response. On one hand, the dispersion may be due to a rotation of the " $\Omega$ " device due to a different solicitation of threads (bonded to the " $\Omega$ ") during the test. On the other hand, especially with respect to the SST-T2 and SST-T3 series, different kinds of failure modes generate the dispersion; the specimens failed by " $\mathrm{B}$ " and " $\mathrm{C}$ " modes are characterized by peaks and displacements significantly lower than the others.

By mutually comparing the three series of specimens, no significant increase of the mean value of the peak load is observed. However, this is also due to the different failure modes occurred in the SST-T2 and SST-T3 series. By looking at the specimens that failed in the same way as the SST-T1 ones, an increase of the maximum load is observed. Nevertheless, even in those cases, the efficiency of the system seems reduced. In fact, the average value of the loading ratio of the textile, $\sigma^{*} / f_{t}$, equal to $78 \%$ for the series of specimens reinforced by one layer of textile, decreases to $39 \%$ and $34 \%$, respectively, in the series SST-T2 and SST-T3. As a matter of fact, increasing the strengthening ratio by overlapping several textile layers caused a significant reduction of the space between the threads, and consequently led to a less performing composite system. The average stress level within the basalt threads of the specimens reinforced by more than one ply results in being much lower than the basalt tensile strength. This aspect is due to the presence of a dense grid that reduces the bond between the matrix and the fibers, as also emphasized by the specimens characterized by a brittle failure mode with an abrupt detachment of the outer layer of mortar from the inner one.

As expected from similar studies in literature, all the specimens reinforced with one ply of basalt textile exhibited a loss of adherence between the textile and the matrix (Figure 7a). In some of the specimens, a mixed failure mode, characterized by the rupture of one or two threads, within the mortar or out of the bonded area, and slipping of the others (failure mode D + F, D + F*) (Figure 7b). This failure mode is due to a non-uniform distribution of axial stresses along basalt bundles that may be due to an accidental load eccentricity. 
a)
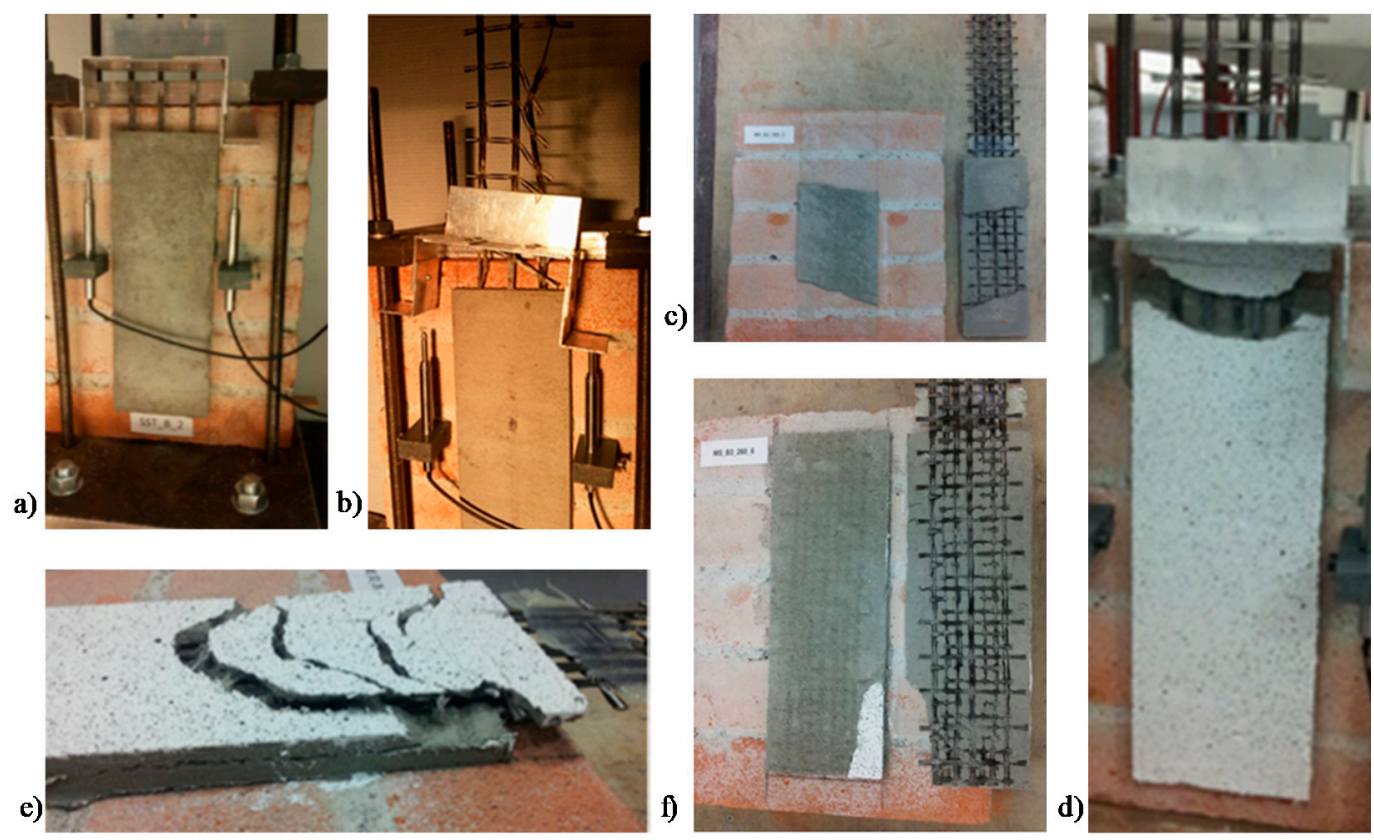

Figure 7. Failure mode of representative specimens: (a) SST-T1-2; (b) SST-T1-3; (c) SST-T2-1; (d) SST-T2-4;

(e) SST-T3-1; (f) SST-T3-3.

As aforementioned, a brittle failure mode was observed in some of the specimens reinforced with overlapped textile layers characterized by a detachment of the outer layer of mortar (Figure 7c,f). As a matter of fact, the arrangement of the overlapped textile layers reduces the width of mesh preventing the mortar to correctly protrude through the voids of the textile during the implementation of the specimens. Consequently, the lack of continuity in the mortar matrix leads to a debonding at the textile-to-matrix interface.

The specimens of the SST-T2 and SST-T3 series showed that a higher capacity exhibited a failure mode due to the slippage of the textile within the mortar (Figure 7d). During several tests, the slippage of the textile has been accompanied by the development of cracks on the outer layer of mortar. In these cases, in accordance with the literature studies on debonding [52], the development of the cracks underline the displacement of the effective bond length from the loaded end to the unloaded end of the sample (Figure 7e).

In the SST-T2 series, the debonding at the matrix-to-substrate interface was observed as well. An inappropriate treatment of the substrate surface during the casting (probably without an adequate humidification of the surface to be reinforced) could justify this behavior. This aspect, together with the lack of continuity within the matrix between the two layers of mortar, emphasizes the key role that a proper manufacturing process plays into the mechanical response of the composite system under investigation.

The energy $\Gamma_{\text {in }}$ dissipated during the post-peak phase (Table 3) is related to the different kind of failure modes recorded; the slippage of the textile inside the mortar matrix (Mode D-Frequently recorded in series T1) allows for a higher dissipation of energy than the slippage between the two layers of mortar (Mode C and E-Frequently recorded in series T2 and T3).

\section{Comparison between Tensile and Shear Bond Responses}

This section presents a comparison between the mechanical response of the BTRM object of study under both shear bond and tensile load conditions. As reported in [7], both types of tests are fundamental for a comprehensive qualification procedure of the composite material. Specifically, the tensile response of BTRM systems is reinforced with either one or two layers of basalt textile, and 
tested according to RILEM recommendations [5], is taken from previous related studies [43,47]. The two series of specimens taken in consideration are as follows:

- Tensile Test with 1 ply of Textile (TT_T1): 5 specimens reinforced by a composite characterized by one ply of textile, and so by three basalt threads (Figure 3a), with a textile density of $220 \mathrm{~g} / \mathrm{m}^{2}$ and a volumetric strengthening ratio of $0.5 \%$;

- Tensile Test with 2 plies of Textile (TT_T2): Five specimens reinforced by a composite characterized by one ply of textile, and so by five basalt threads (Figure 3b), with a textile density of $367 \mathrm{~g} / \mathrm{m}^{2}$ and a volumetric strengthening ratio of $0.9 \%$.

As seen, the two series of specimens, TT-T1 and TT-T2, are respectively reinforced with the same textile arrangements adopted in SST-T1 and SST-T2 series of specimens.

Tensile response in terms of stress-strain curves of TT-T1 and TT-T2 series of specimens is shown in Figure 8. Stress is computed by considering the bared cross-section of the textile.

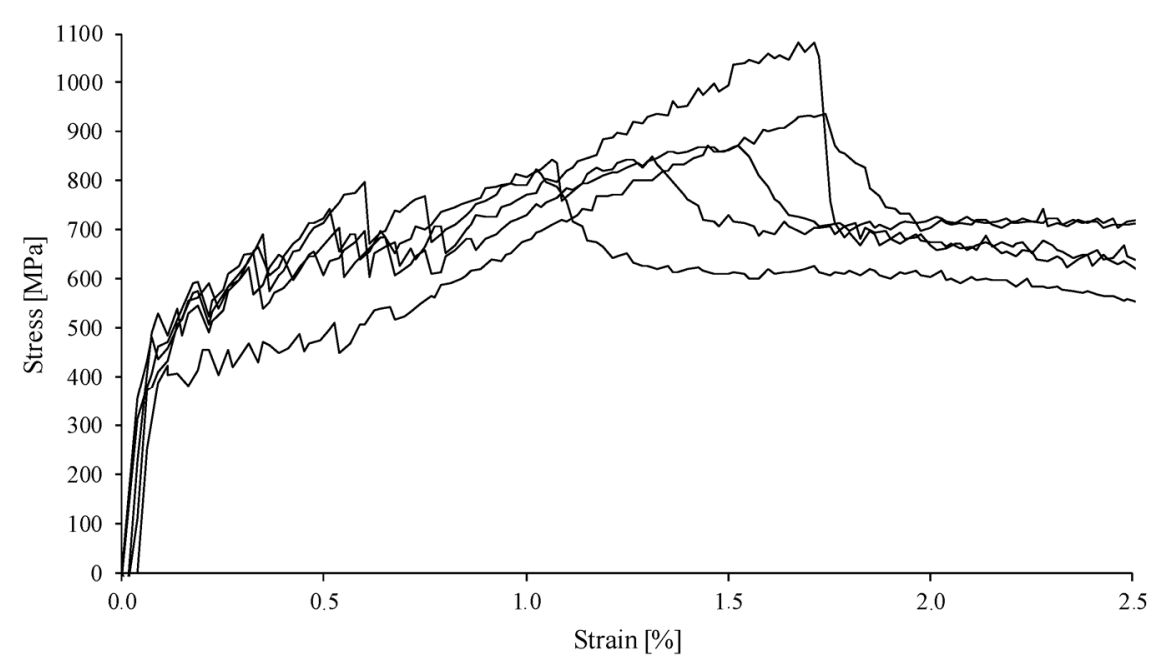

(a)

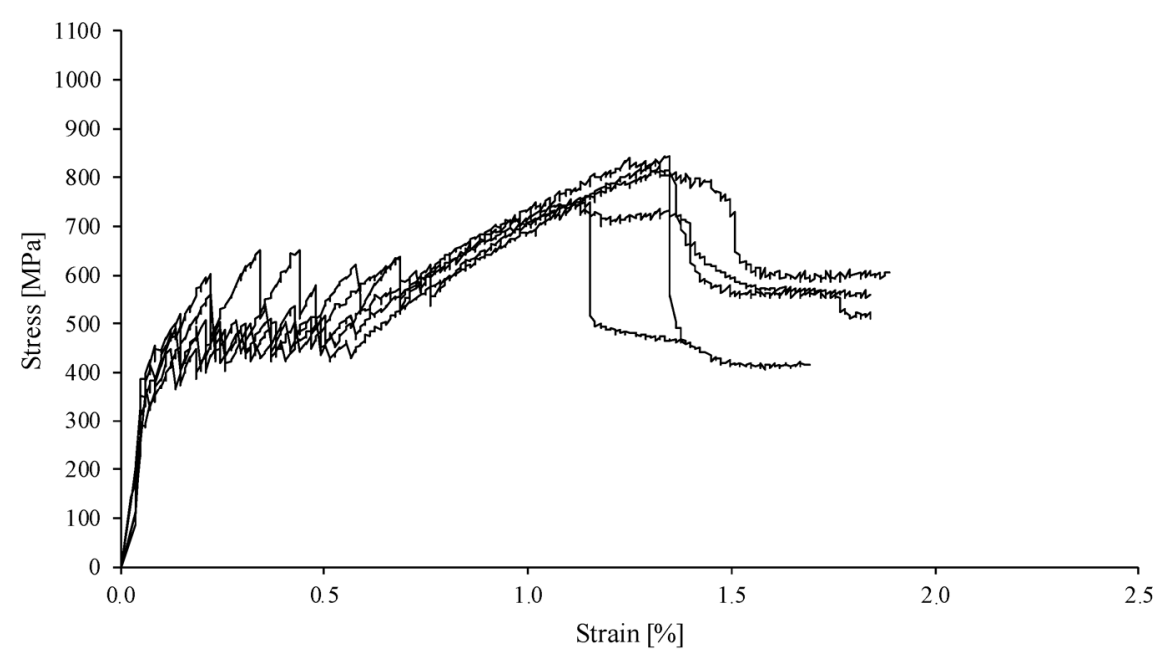

(b)

Figure 8. Stress-strain curves of tensile tests on series: (a) TT_T1; (b) TT_T2 (Data from [43]).

By looking at the stress-strain curves, the tensile response of the BTRM composite does not significantly change by increasing the amount of textile reinforcement. Both the series of specimens 
are characterized by a first linear branch followed by a stage characterized by the development of several cracks in the matrix up to a third stage in which the response is mainly governed by the reinforcing textile. Specimens reinforced by a higher amount of textile exhibited a cracks development characterized by fissures greater in number and closer each other. With respect to the stiffness of the system in the third stage, an average value of $435.5 \mathrm{MPa}$ (Co.V. $21 \%$ ) and $453.4 \mathrm{MPa}(19 \%)$ was obtained respectively for the TT-T1 and TT-T2 series of specimens. This aspect emphasized that, in the third stage, the response is mainly governed by the textile; hence, even by increasing the textile amount, no significant change is observed in terms of stress-strain response. Tensile tests have been carried out clamping the coupons at the two edges by applying a transversal pressure to lock the composite within the clamps.

However, the rupture of the textile hardly occurred, and the failure modes mainly were characterized by a loss of adherence at the textile-to-matrix interface in proximity of one of the two edges of the specimens. This is the reason why the maximum stress achieved in the textile is lower than the basalt strength. By comparing the shear bond response of series SST-T1 and SST-T2, respectively reinforced by one and two overlapped plies of textile, the same trend shown in tension is not confirmed. In fact, as widely discussed in the paragraph above, by increasing the amount of textile, the shear performance of the composite system significantly reduces due to adherence problems related to the decrease of the textile grid spaces caused by overlapping more textile layers.

This discrepancy between the tensile and shear bond response can be seen in Table 4 where the textile exploitation ratio mean values are reported for TT and SST series, while, for the specimens $\mathrm{T} 1$ in shear conditions, the exploitation ratio decreases by about the $10 \%$ with respect to the tensile conditions; this gap decreases up to about $50 \%$ in the case of $\mathrm{T} 2$ series.

Table 4. Main values of the textile exploitation ratio in tension and shear bond load conditions.

\begin{tabular}{cccccc}
\hline \multirow{2}{*}{ Tensile Tests } & $\sigma^{*} / f_{t}$ & (Co.V.) & Single Shear & $\sigma^{*} / f_{t}$ & (Co.V.) \\
\cline { 2 - 6 } & $\%$ & $\mathbf{\%}$ & Tests & $\%$ & $\%$ \\
\hline TT-T1 & 87 & $(10)$ & SST-T1 & 78 & $(21)$ \\
TT-T2 & 76 & $(6)$ & SST-T2 & 39 & $(22)$ \\
\hline
\end{tabular}

The boundary conditions justify the different behavior of TT and SST specimens. The application of orthogonal stresses to the specimen extremities by means of hydraulic grips prevent the debonding between the mortar and the textile until the achievement of a failure at the clamp. The application of loading on the free extremity of textile during the SST tests promotes the debonding between textile rowing and composite matrix.

The experimental evidence confirms the key role of boundary conditions and the importance of analyzing both the tensile and the shear bond behavior of TRM systems to totally characterize their mechanical behavior. Moreover, by also taking into account the nature of the substrate, the shear bond test appears as an essential step to investigate the composite system for designing purposes.

\section{Conclusions}

This paper presents an experimental analysis about the adhesion between basalt-TRM and clay-brick masonry. The main findings of the research are highlighted as follows:

- $\quad$ B-TRM systems characterized by basalt density of $220 \mathrm{gr} / \mathrm{m}^{2}$ (1 layer of textile) are characterized by a mechanical response in which the maximum capacity is mainly governed by the loss of adherence at the fiber-to-matrix interface;

- The failure mode and the load capacity recorded show that a high density of textile in the middle of composite (two and three layers of textile, respectively 367 and $527 \mathrm{gr} / \mathrm{m}^{2}$ ) reduce the adherence between the upper and lower layer of mortar matrix. By looking at the results in terms of stress, the fiber loading resulted in being lower in specimens with higher amount of textile reinforcement; 
- $\quad$ the textile grid size and the manufacturing process play a key role in the definition of a TRM system in which an appropriate continuity of the matrix allows the system to correctly work as a composite material.

- the comparison between tensile and shear bond response emphasizes the importance of shear tests to investigate the adhesion behavior otherwise not shown by only characterizing the material in tension.

Finally, basalt fabrics confirmed their potential as reinforcement in TRM systems, though further studies are needed to improve their adhesion with the mortar matrix. These studies, dealing with both shape and texture of fabrics and mortar composition, are among the future developments of the present work.

Author Contributions: All of the authors contributed to the conceptualization and to the methodology of the research. G.F. performed the experimental activities, analyzed the data, and prepared the manuscript under the supervision of C.C., E.M., and A.G.; all of the authors reviewed and edited the final version of the paper. Finally, the funding acquisition was coordinated by C.C.

Funding: The present study is part of the activity carried out by the First Author at the Laboratory of Composite Materials for Constructions (University C.B. Lyon1) whose permanence at the research institution was financed by an international scholarship within the research project "BQR Accueil EC 2015" of University Claude Bernard Lyon1.

Acknowledgments: The authors gratefully acknowledge the companies San Marco Terreal and Fyfe for providing the materials tested in the experimental research presented in this paper.

Conflicts of Interest: The authors declare no conflict of interest.

\section{References}

1. Tetta, Z.C.; Koutas, L.N.; Bournas, D.A. Textile-reinforced mortar (TRM) versus fiber-reinforced polymers (FRP) in shear strengthening of concrete beams. Compos. Part B Eng. 2015, 77, 338-348. [CrossRef]

2. Bisby, L.; Stratford, T.; Smith, J.; Halpin, S. Comparative performance of fibre reinforced polymer and fibre reinforced cementitious mortar strengthening systems in elevated temperature service environments. In Proceedings of the Structural Faults and Repair 2010, Edinburgh, UK, $15-17$ June 2010; Engineering Technics Press: Edinburgh, UK, 2010.

3. ACI 549.4R-13, Guide to Design and Construction of Externally Bonded Fabric-Reinforced Cementitious Matrix (FRCM) Systems for Repair and Strengthening Concrete and Masonry Structures; ACI Committee 549: Farmington Hills, MI, USA, 2013.

4. AC434, Acceptance Criteria for Masonry and Concrete Strengthening Using Fiber-Reinforced Cementitious Matrix (FRCM) and Steel Reinforced Grout (SRG) Composite Systems; ICC Evaluation Service, LLC: Birmingham, AL, USA, 2018.

5. RILEM Technical Committee 232-TDT (Wolfgang Brameshuber). Recommendation of RILEM TC 232-TDT: Test methods and design of textile reinforced concrete. Uniaxial tensile test: Test method to determine the load bearing behaviour of tensile specimens made of textile reinforced concrete. Mater. Struct. 2016, 49, 4923-4927. [CrossRef]

6. de Felice, G.; Aiello, M.A.; Caggegi, C.; Ceroni, F.; De Santis, S.; Garbin, E.; Gattesco, N.; Hojdas, Ł.; Krajewski, P.; Kwiecień, A.; et al. Recommendation of RILEM Technical Committee 250-CSM: Test method for textile reinforced mortar to substrate bond characterization. Mater. Struct. 2018, 51, 95. [CrossRef]

7. Linea Guida per la Identificazione, la Qualificazione ed il Controllo di Accettazione di Compositi Fibrorinforzati a Matrice Inorganica (FRCM) da Utilizzarsi per il Consolidamento Strutturale di Costruzioni Esistenti; Consiglio Superior dei Lavori Pubblici-Servizio Tecnico Centrale: Rome, Italy, 2018.

8. CNR-DT 215/2018, Istruzioni per la Progettazione, L'esecuzione ed il Controllo di Interventi di Consolidamento Statico Mediante L'utilizzo di Compositi Fibrorinforzati a Matrice Inorganica; CNR Commissione di Studio per la Predisposizione e L'analisi di Norme Tecniche Relative Alle Costruzioni: Rome, Italy, 2018.

9. De Santis, S.; de Felice, G. Tensile behaviour of mortar-based composites for externally bonded reinforcement systems. Compos. Part B 2015, 68, 401-413. [CrossRef]

10. Carozzi, F.G.; Poggi, C. Mechanical properties and debonding strength of Fabric Reinforced Cementitious Matrix (FRCM) systems for masonry strengthening. Compos. Part B 2015, 70, 215-230. [CrossRef] 
11. Arboleda, D.; Carozzi, F.G.; Nanni, A.; Poggi, C. Testing procedures for the uniaxial tensile characterization of fabric reinforced cementitious matrix (FRCM) composites. J. Compos. Constr. 2016, 20, 04015063. [CrossRef]

12. D'Antino, T.; Papanicolaou, C. Mechanical characterization of textile reinforced inorganic-matrix composites. Compos. Part B 2017, 127, 78-91. [CrossRef]

13. Saidi, M.; Gabor, A. Use of distributed optical fibre as a strain sensor in textile reinforced cementitious matrix composites. Measurement 2019, 140, 323-333. [CrossRef]

14. Nobili, A. Durability assessment of impregnated Glass Fabric Reinforced Cementitious Matrix (GFRCM) composites in the alkaline and saline environments. Constr. Build. Mater. 2016, 105, 465-471. [CrossRef]

15. Nobili, A.; Signorini, C. On the effect of curing time and environmental exposure on impregnated Carbon Fabric Reinforced Cementitious Matrix (FRCM) composite with design considerations. Compos. Part B 2017, 112, 300-313. [CrossRef]

16. Donnini, J.; De Caso y Basalo, F.; Corinaldesi, V.; Lancioni, G.; Nanni, A. Fabric-reinforced cementitious matrix behaviour at high-temperature: Experimental and numerical results. Compos. Part B 2017, 108, 108-121. [CrossRef]

17. Tran, M.T.; Hong Vu, X.; Ferrier, E. Experimental and analytical analysis of the effect of fibre treatment on the thermomechanical behaviour of continuous carbon textile subjected to simultaneous elevated temperature and uniaxial loadings. Constr. Build. Mater. 2018, 183, 32-45. [CrossRef]

18. De Munck, M.; El Kadi, M.; Tsangouri, E.; Vervloet, J.; Verbruggen, S.; Wastiels, J.; Tysmans, T.; Remi, O. Influence of environmental loading on the tensile and cracking behaviour of textile reinforced cementitious composites. Constr. Build. Mater. 2018, 181, 325-334. [CrossRef]

19. Colombo, I.G.; Colombo, M.; Di Prisco, M. Tensile behavior of textile reinforced concrete subjected to freezing-thawing cycles in un-cracked and cracked regimes. Cem. Concr. Res. 2015, 73, 169-183. [CrossRef]

20. D'Ambrisi, A.; Feo, L.; Focacci, F. Experimental and analytical investigation on bond between Carbon-FRCM materials and masonry. Compos. Part B 2013, 46, 15-20. [CrossRef]

21. Carozzi, F.G.; Milani, G.; Poggi, C. Mechanical Properties and numerical modeling of Fabric Reinforced Cementitious Matrix (FRCM) systems for strengthening of masonry structures. Compos. Struct. 2014, 107, 711-725. [CrossRef]

22. De Felice, G.; De Santis, S.; Germendia, L.; Ghiassi, B.; Larrinaga, P.; Lourenço, P.B.; Oliveira, D.V.; Paolacci, F.; Papanicolaou, C.G. Mortar-based systems for externally bonded strengthening of masonry. Mater. Struct. 2014, 47, 2021-2037. [CrossRef]

23. Donnini, J.; Corinaldesi, V.; Nanni, A. Mechanical properties of FRCM using carbon fabrics with different coating treatments. Compos. Part B 2016, 88, 220-228. [CrossRef]

24. D'Antino, T.; Gonzalez, J.; Pellegrino, C.; Carloni, C.; Sneed, L.H. Experimental investigation of glass and carbon FRCM composite materials applied onto concrete supports. Appl. Mech. Mater. 2016, 847, 60-67. [CrossRef]

25. Bencardino, F.; Condello, A.; Ashour, A.F. Single-lap shear bond tests on Steel Reinforced Geopolymeric Matrix-concrete joints. Compos. Part B 2017, 110, 62-71. [CrossRef]

26. Codispoti, R.; Oliveira, D.; Olivito, R.S.; Lourenço, P.B.; Fangueiro, R. Mechanical performance of natural fiber-reinforced composites for strengthening of masonry. Compos. Part B 2015, 77, 74-83. [CrossRef]

27. Olivito, R.S.; Cevallos, O.A.; Carrozzini, A. Development of durable cementitious composites using sisal and flax fabrics for reinforcement of masonry structures. Mater. Des. 2014, 57, 258-268. [CrossRef]

28. Olivito, R.S.; Codispoti, R.; Cevallos, O.A. Bond behaviour of Flax-FRCM and PBO-FRCM composites applied on clay bricks: Experimental and theoretical study. Compos. Struct. 2016, 146, 221-231. [CrossRef]

29. Ferrara, G.; Pepe, M.; Martinelli, E.; Tolêdo Filho, R.D. Influence of an impregnation treatment on the morphology and mechanical behaviour of flax yarns embedded in hydraulic lime mortar. Fibers 2019, 7, 30. [CrossRef]

30. Ferrara, G.; Coppola, B.; Di Maio, L.; Incarnato, L.; Martinelli, E. Tensile strength of flax fabrics to be used as reinforcement in cement-based composites: Experimental tests under different environmental exposures. Compos. Part B 2019, 168, 511-523. [CrossRef]

31. D'Antino, T.; Sneed, L.H.; Carloni, C.; Pellegrino, C. Influence of the substrate characteristics on the bond behaviour of PBO FRCM concrete joints. Constr. Build. Mater. 2015, 101, 838-850. [CrossRef] 
32. Caggegi, C.; Carozzi, F.G.; De Santis, S.; Fabbroncino, F.; Focacci, F.; Hojdys, Ł.; Lanoye, E.; Zuccarino, L. Experimental analysis on tensile and bond properties of $\mathrm{PBO}$ and aramid fabric reinforced cementitious matrix for strengthening masonry structures. Compos. Part B 2017, 127, 175-195. [CrossRef]

33. Carozzi, F.G.; Bellini, A.; D’Antino, T.; de Felice, G.; Hojdys, Ł.; Laghi, L.; Lanoye, E.; Micelli, F.; Panizza, M.; Poggi, C. Experimental investigation of tensile and bond properties of Carbon-FRCM composites for strengthening masonry elements. Compos. Part B 2017, 128, 100-119. [CrossRef]

34. De Santis, S.; Ceroni, F.; de Felice, G.; Fagone, M.; Ghiassi, B.; Kwiecien, A.; Lignola, G.P.; Morganti, M.; Santandrea, M.; Valluzzi, M.R.; et al. Round Robin Test on tensileand bond behaviour of Steel Reinforced Grout systems. Compos. Part B 2017, 127, 100-120. [CrossRef]

35. Leone, M.; Aiello, M.A.; Balsamo, A.; Carozzi, F.G.; Ceroni, F.; Corradi, M.; Gams, M.; Garbin, E.; Gattesco, N.; Krajewski, P.; et al. Glass fabric reinforced cementitious matrix: Tensile properties and bond performance on masonry substrate. Compos. Part B 2017, 127, 196-214. [CrossRef]

36. Ascione, L.; De Felice, G.; De Santis, S. A qualification method for externally bonded fibre reinforced cementitious matrix (FRCM) strengthening systems. Compos. Part B 2015, 78, 497-506. [CrossRef]

37. Kaw, A.K. Mechanics of Composite Materials, 2nd ed.; Taylor \& Francis Group, LLC, Abington: Oxfordshire, UK, 2006.

38. Ombres, L. Analysis of the bond between Fabric Reinforced Cementitious Mortar (FRCM) strengthening systems and concrete. Compos. Part B 2015, 69, 418-426. [CrossRef]

39. De Santis, S.; De Felice, G. Steel reinforced grout systems for the strengthening of masonry structures. Compos. Struct. 2015, 134, 533-548. [CrossRef]

40. Deàk, T.; Czigàny, T. Chemical composition and mechanical properties of basalt and glass fibres: A comparison. Text. Res. J. 2009, 79, 645-651. [CrossRef]

41. Sim, J.; Park, C.; Moon, D.Y. Characterisation of basalt fibres as a strengthening material for concrete structures. Compos. Part B 2005, 36, 504-512. [CrossRef]

42. Fiore, V.; Scalici, T.; Di Bella, G.; Valena, A. A review on basalt fibre and its composites. Compos. Part B 2015, 74, 74-94. [CrossRef]

43. Lignola, G.P.; Caggegi, C.; Ceroni, F.; De Santis, S.; Krajewski, P.; Lourenço, P.B.; Morganti, M.; Papanicolaou, C.; Pellegrino, C.; Pellegrino, A.; et al. Performance assessment of basalt FRCM for retrofit applications on masonry. Compos. Part B 2017, 128,1-18. [CrossRef]

44. Larrinaga, P.; Chastre, C.; Biscaia, H.C.; San-José, J.T. Experimental and numerical modeling of basalt textile reinforced mortar behaviour under uniaxial tensile stress. Mater. Design 2014, 55, 66-74. [CrossRef]

45. Marcari, G.; Basili, M.; Vestroni, F. Experimental investigation of tuff masonry panels reinforced with surface bonded basalt textile-reinforced mortar. Compos. Part B 2017, 108, 131-142. [CrossRef]

46. Harajli, M.; Elkhatib, H.; San-José, J.T. Static and cyclic out-of-plane response of masonry walls strengthened using textile-mortar system. J. Mater. Civ. Eng. 2010, 22, 1171-1180. [CrossRef]

47. Caggegi, C.; Lanoye, E.; Djama, K.; Bassil, A.; Gabor, A. Tensile behavior of a basalt TRM strengthening system: Influence of mortar and reinforcing textile ratios. Compos. Part B 2017, 130, 90-120. [CrossRef]

48. De Felice, G.; Aiello, M.A.; Bellini, A.; Ceroni, F.; De Santis, S.; Garbin, E.; Leone, M.; Lignola, G.P.; Malena, M.; Mazzotti, C.; et al. Experimental characterisation of composite-to-brick masonry shear bond. Mater. Struct. 2015, 49, 2581-2596. [CrossRef]

49. San Marco Terreal Company Website. Available online: https://www.sanmarco.it/ (accessed on 14 May 2019).

50. EN 196-1:1994. Methods of Testing Cement-Part 1: Determination of Strength; European Committee for Standardization: Brussels, Belgium, 1994.

51. Fyfe Company Website. Available online: https://www.aegion.com/about/our-brands/fyfe (accessed on 14 May 2019).

52. Caggegi, C.; Sciuto, D.; Cuomo, M. Experimental study on effective bond length of basalt textile reinforced mortar strengthening system: Contribution of digital image correlation. Measurement 2018, 129, 119-127. [CrossRef]

(C) 2019 by the authors. Licensee MDPI, Basel, Switzerland. This article is an open access article distributed under the terms and conditions of the Creative Commons Attribution (CC BY) license (http://creativecommons.org/licenses/by/4.0/). 